breakdown of the cell wall and the nature and origin of the substances responsible for the development of colour, flavour and odour.

The Board points out the necessity of a close contact with commercial practice and describes the different steps taken to ensure the application of laboratory results in the trades concerned: thus a small laboratory is being established, in the vicinity of Smithfield Market, London, on the lines of the Covent Garden Laboratory (which is also being extended), to act as a centre for liaison with the trade. Similarly, arrangements have been made with Messrs. Crosse and Blackwell, Ltd., for the trial at Peterhead of a kiln for the smoking of fish, which is designed in accordance with the principles established at the Torry Research Station. The Board also co-operates with similar bodies in the Dominions and is stimulating research in other parts of the Empire, since it is usually essential that the problems of storage should be studied as soon as the produce has been prepared for the market, and this is not possible in Great Britain in the case of such important fruits as the orange and banana.

The report of the Board refers as usual to the changes which have taken place in its composition during the year: Prof. C. H. Lees and Sir Thomas Middleton have been appointed additional members. The Engineering Committee has been reconstituted with the following membership: Prof. C. H. Lees (chairman), Prof. E. H. Lamb, Prof. G. I. Taylor and Prof. H. E. Watson. The bulk of the report is devoted to the report of the Director of Food Investigation, Mr. E. Barnard, and is divided into sections dealing with meat, poultry and eggs, pork bacon and hams, fish, fruit and vegetables, canning and engineering. The researches at present in progress are described. by the investigators who are carrying them out.
One or two may be referred to here, to indicate some of the problems involved and the results obtained.

Two effects of the treatment of the pig immediately before slaughter on the quality of the carcass have been measured. First, fasting has been shown to increase the thickness of the flank. Secondly, the muscle of pigs overheated before slaughter has a higher electrical resistance than that of rested pigs; low resistance facilitates the penetration of salt during dry salting. Farm. killed pigs were found to have a low resistance as compared with factory-killed, and this difference was traced to the shaking which the carcasses undergo during transport to the factory.

Trials of the refrigerated gas-storage of Conference pears have been made with good results: flavour, texture and appearance are retained after long periods of storage. If soft fruits are given a preliminary heating, there is little loss of the power to set, during storage in the frozen state at $-7^{\circ} \mathrm{C}$., a temperature which inhibits the growth of moulds, or during storage with sulphurous acid. Without the preliminary heating, the power to set in jammaking is more or less rapidly lost. Apples and plums, however, do not suffer this loss under the same conditions. It has been shown that the amount of ethylene evolved by ripe apples and bananas is sufficient to initiate the ripening of green, unripe bananas. The passage of air containing one part per million of ethylene over the green fruit also causes it to begin ripening after 24 hours, but with fruit that has just started to ripen the mixture has little effect. These experiments suggest that the efficiency of ripening rooms for bananas heated with coal gas burners may be due to a slight leakage of the gas supply permitting a low concentration of ethylene in the air surrounding the fruit.

\title{
The Upper Palæolithic in the Light of Recent Discovery*
}

\author{
By Miss D. A. E. Garrod
}

$\mathrm{T}$ $\mathrm{HE}$ last twelve years have seen a new impetus given to prehistoric studies by the multiplication of researches outside Europe. Excavations in Africa, the Near East, Asiatic Russia and China have opened up a new field for speculation, and at the same time have revealed the unsuspected complexity of many problems which to De Mortillet and other pioneers seemed relatively simple. Gone for ever is the straightforward succession of

* From the presidential address to Section H (Anthropology) of the British Association, delivered at Blackpool on September 10.
Palæolithic cultures from Chellian to Magdalenian as laid down in the Musée Préhistorique. Even so early as 1912, when Breuil produced his classic paper on the subdivisions of the Upper Palæolithic, its foundations were sapped, and the discoveries of the last decade have merely completed its demolition as a system of world-wide application.

In the old system the Palæolithic cultures appeared as a straightforward succession with clearcut horizontal divisions, as in a diagrammatic geological section. The main outline of a new 
pattern is, however, already beginning to appear. We can distinguish in the Old Stone Age three cultural elements of primary importance. These are manifested in the so-called hand-axe industries, flake industries and blade industries, and we know that the first two, at any rate, run side by side as far back as we can see, and we are beginning to realize that the origins of the third may have to be sought much farther back than we had suspected. Only a moment of reflection is needed to see that we have here the old divisions of Lower, Middle and Upper Palæolithic, but with a new axis.

These general considerations are necessary to clear the ground for the subject with which I am going to deal-those cultures the appearance of which in Europe towards the close of the Pleistocene marks the extinction of Neanderthal man and the arrival of Homo sapiens. In the main these are essentially blade cultures, though in certain areas industries of Mousterian tradition lingered on into Upper Palæolithic times. Now it is clear that these blade cultures must have passed through the early stages of their development somewhere outside Europe, during Middle or even Lower Palæolithic times, but we have at present only the faintest clues as to how and where that development took place.

The general conclusions which can be drawn from the material at our disposal may be summarized as follows. A point which stands out at once, and very clearly, is the diversity of the strains which have so far been grouped together under the name Aurignacian. So long as we were dealing only with Western Europe this did not matter very much, as everyone knew what was meant by the Lower, Middle and Upper Aurignacian, but when we come to regions in which the sequence is not the same, the use of these terms, with their chronological implications, is definitely misleading. Peyrony proposes to retain the label Aurignacian for the culture so far known as Middle Aurignacian, and to group all the industries characterized by the blunted-back blade under the heading Perigordian. This undoubtedly corresponds with a first, very important distinction, which has been recognized for some time, but it does not go far enough. Perigordian, like the former Aurignacian, is made to cover too much. In spite of fundamental resemblances which certainly suggest relationship, it is doubtful if the passage from the Chatelperron to the Gravette level is the simple evolutionary process supposed by Peyrony. The blade cultures, after all, have an immensely wide distribution, and it is unlikely that the key to their development is to be found in southern France.

If we take more distant regions into account, it becomes clear that the French sequence is the result of successive immigrations, superimposed, perhaps, on a certain amount of local variation and development in place. Since, however, this sequence is so familiar, and has for so long been accepted as a standard, I propose to make it my point of departure, and to examine its various stages in the light of the evidence now available, trying to trace each one back to its original centre. Afterwards it will be possible to shift our point of observation, and taking a wider view of the distribution map thus plotted, to see what general pattern emerges.

The first blade industry to reach Western Europe is that of the Chatelperron stage, Peyrony's Perigordian I, which is the former lower Aurignacian. The distinctive implement of this industry is, of course, the curved blunted-back blade, or Chatelperron point. The Chatelperron levelwhich, for convenience, I shall provisionally call Chatelperronian-has not so far been found in Central and Eastern Europe, but a similar though not identical industry occurs at the base of the Upper Palæolithic sequence in Palestine. This, however, is less primitive in appearance than that of France, and seems already to be in process of evolution towards something resembling the La Gravette stage. The Lower Capsian, which is characterized by curved points, was formerly regarded as the parent of the Chatelperron industry, but Vaufrey demolished this theory by demonstrating that it is later in time. On the other hand, the Lower Kenya Aurignacian appears to be more or less of Chatelperron type, and may be in part contemporary with this stage in France. We thus have at the beginning of the Upper Palæolithic three areas which may in a wide sense be called Chatelperronian, two of which, Palestine and East Africa, may have been in touch with each other through Arabia and across the Bab-elMandeb, while the third remains apparently isolated. The problem of how the Chatelperronian entered Western Europe without leaving any traces on the way is one that awaits solution.

Although the Chatelperronian only appears as a distinct industry at the beginning of the Upper Palæolithic, we can trace its essential features much farther back than this. The LevalloisoMousterian of Palestine, which covers a very long period, has yielded throughout a small proportion of well-made curved points, burins and end-scrapers, and in the Tabun cave on Mount Carmel, typical Chatelperron points, end-scrapers, and blades with abrupt retouch were relatively abundant all through a well-determined zone within the Final Acheulean. In Kenya also Leakey has found backed blades associated with the Upper Acheulean, and he suggests that the so-called Lower Aurignacian - the Chatelperronian-may have 
developed from the contact of the Acheulean and Levalloisian cultures, the makers of the Acheulean hand-axes borrowing from the Levalloisian the idea of making use of long narrow blades. This is not impossible, of course, but it should be noted that in the Upper Acheulean of Palestine, as in Western Europe, the flake industry which is actualiy associated with the hand-axes is in the Clactonian tradition, and the Chatelperronian tools look markedly out of place and intrusive, while in the Kharga Oasis, where a Levalloisian flake industry actually forms part of the late Acheulean, no Chatelperronian forms have been found.

I should like to put forward the alternative suggestion that the Chatelperronian already had an independent existence at this time, having developed in some centre still unknown, and that it is an intrusive element in the Acheulean. In trying to trace this centre, we must take into account the fact, which seems to me significant, that the two regions in which the presence of backed blades in the late Acheulean is clearly established are precisely those in which a distinct Chatelperronian industry appears at the beginning of the Upper Palæolithic. If-as I am inclined to do-we reject the theory that the Chatelperronian developed within the Acheulean, we cannot accept either Palestine or East Africa as its original home, but must place this somewhere within reach of both. An Asiatic centre seems inevit. able, but it is impossible at present to be more precise.

After the early stages of the Upper Palæolithic, the Chatelperronian proper apparently ceases to exist. In Palestine, however, the Chatelperron point reappears unexpectedly in the final stage, which must be roughly contemporary with the Magdalenian, and it is present in the Lower Capsian at approximately the same moment. Now, Vaufrey's theory of the late arrival of the Capsian still leaves us in the dark as to its origin. In its general lines it is unlike either the Sabylian or the blade industries of Palestine. We have seen, however, that the Upper Kenya Aurignacian is a nearly typical Capsian, which seems to have developed in place from the so-called Lower Kenya Aurignacian. I would suggest that East Africa may possibly be the centre of origin of the Capsian, which would thus enter Little Africa already fully developed by way of the Sahara. The Capsian would thus derive many of its features direct from the Chatelperronian, though outside influences may also have played their part, especially in the development of the microlithic element. It is, for example, unlikely that so specialized a type as the micro-burin should have developed independently in the Sabylian and the Capsian.
As for the peculiar industry which closes the Upper Palæolithic sequence in Palestine, it is quite definitely Aurignacian rather than Capsian, in spite of the presence of Chatelperron points, and it may conceivably be a local development, arising on the fringes of our hypothetical Chatelperronian centre and the Aurignacian province of the Near East.

Turning back to the Western European sequence, we now reach the Aurignacian proper, the former Middle Aurignacian. Peyrony claims that this does not represent a real break in the sequence, but that the Perigordian continued to develop in certain sites side by side with the neighbouring Aurignacian. The stratigraphical evidence for this is, however, insufficient. Even if there is a certain overlap, as is probable, all the known facts are in favour of a general separation of the Chatel. perron and La Gravette levels by the layers containing the Aurignacian.

This industry can be traced right across Europe, through Lower Austria, Hungary, Rumania, the Crimea, Transcaucasia and Anatolia into Palestine, where it is very abundant and covers a much longer period than in the West. This suggests that the East Mediterranean coast is not very far from the Aurignacian centre of dispersion, and $I$ would suggest tentatively that this should be sought somewhere in the Iranian plateau.

It is an open question and a very difficult one, how far the Aurignacian and Chatelperronian have ultimately a common origin. Certain forms, such as the burin and end-scraper, are found in practically all blade industries, but the Aurignacian, with its use of types derived from cores and con. sequent development of a fluting technique, has distinctive features which point at least to independent evolution from an early date.

The next stages in the French sequence are those of La Gravette and Font-Robert, formerly grouped together as Upper Aurignacian, which Peyrony has labelled Perigordian IV and V. This industry has clear affinities with the Capsian, and in view of the possibility that the Lower Capsian may be roughly contemporary with it, the question of African influence must be re-examined at this point. For various reasons, however, I think it must be ruled out. Already in the Lower Capsian two very distinctive forms, the micro-burin and the microlithic lunate, are present, and if this industry were the parent of the Gravette-FontRobert stage of Europe it would seem inevitable that these should occur there also. In fact, however, they enter Western Europe only with the Tardenoisian culture at a much later date. Again, if the Lower Capsian passed into France it must have been through the Iberian Peninsula, and we have seen that in that region Capsian influences 
appear only at the close of the Upper Palæolithic sequence. Finally, the Gravette-Font-Robert industry has a very wide distribution in central and eastern Europe, and its remarkable development in this region points rather to a Eurasiatic origin. If further evidence were needed, one could cite the complete absence in Little Africa of the very distinctive female statuettes which are constantly associated with this culture in Europe. It does not follow that there is no link between the Capsian and the Gravette-Font-Robert industry ; I would suggest that both are derived from the Chatelperronian, but that their common features are due in part to convergent development, certain forms, such as the Gravette point, being evolved almost necessarily from their Chatelperronian prototypes.

I have suggested that an Eastern origin is indicated for the Gravette-Font-Robert industry, and we must now examine this rather more closely. In France the distinction between the Gravette level with its typical blunted-back blades, and the overlying Font-Robert level with tanged and shouldered points is quite clear, but the two are nevertheless very closely related. In Central and Eastern Europe the shouldered point stage predominates and is associated with a distinctive decorative art and apparently a great development of the cult of which female statuettes are the expression. I would suggest for these two very closely related levels the names of Lower Gravettian and Upper Gravettian respectively, the label Grimaldian being reserved for the special development and prolongation of the Upper Gravettian in the Italian Peninsula.

The theory of an eastern centre of dispersion for the Gravettian is based, of course, on this exceptional development in Central and Eastern Europe. I am influenced also by the fact that the female statuettes, the close connexion of which with the Upper Gravettian is incontestable, are very abundant in Russia, but occur only sporadically in Western Europe, where they have an unmistakably alien appearance in comparison with the indigenous naturalistic animal art which had already begun to develop in the Aurignacian.

Assuming an Eastern origin, we cannot regard Central Europe as the centre of dispersion, because we have clear evidence that the Gravettian is there preceded by the Aurignacian proper. In South Russia it is indeed the oldest blade industry so far found, but the geological evidence does not suggest that it is necessarily very early, though it may quite well be contemporary with the Aurignacian of the West. I do not think, however, that the centre of dispersion can lie very much farther to the east, because the lithic industry of Malta, which must be approximately contemporary, is not Gravettian at all, though the presence of statuettes and certain decorative motifs suggests either that Siberia was reached by influences from South Russia or that the particular cult of which female statuettes were the expression came to the Gravettian from the Far East.

We must now consider by what route an industry ancestral to the Gravettian could have passed into North-east Europe from our hypothetical Chatelperronian centre. We have seen that in Palestine the true Gravettian is absent, and that in southern Kurdistan it probably represents a relatively late migration from Russia. In Palestine, however, the Chatelperronian level which lies at the base of the Upper Palæolithic sequence already shows signs of evolution towards the Gravettian type, and it is possible that an industry of this character had already penetrated into the neighbourhood of the South Russian plain before the westward moving Aurignacian invasion had reached the Mediterranean coast.

I need not dwell on the Solutrean episode, which forms the next stage in the French sequence, as this is already well known and understood. The only addition to our knowledge in recent years has been the demonstration that the Solutrean penetrated farther to the east than was originally supposed from its Hungarian centre.

With the Magdalenian we reach a stage when migration on a wide scale gives way to local variations of the cultures already in possession. Apart from the Magdalenian itself, which is undoubtedly the most interesting and the most vital of these variations, we have the Grimaldian in Italy, in South Russia a degenerate industry of Gravettian tradition, in Palestine a kind of hybrid Aurignacian which may extend into the Crimea, in Egypt the Sabylian, in England the Creswellian, while the retreat of the ice sheet in northern Europe made way for the Hamburg culture which is apparently derived from the Upper Gravettian. To round off completely the story of the Palæolithic blade cultures it would be necessary to pursue a number of these branches into the Mesolithic, but the close of the Pleistocene, for general purposes, marks the end of an epoch in human history, and although no catastrophic change is visible, with the dawn of the Mesolithic a new order is already on its way.

If we now take a last general view of this theoretical picture, we see the Chatelperronian, the earliest identifiable phylum of the blade cultures, already emerging in Lower Palæolithic times, in some as yet unidentified Asiatic centre. Ultimately it sends out two branches, one into East Africa, to give rise to the Capsian, the other into North-east Europe, to develop into the Gravettian. Meanwhile another stock, the 
Aurignacian, pushes westward, and separates these two great provinces. From the Aurignacian and Gravettian centres migrations pour into Central and Eastern Europe along the southern edge of the ice-sheet, and cultures which in their homelands tend to remain distinct and exclusive succeed and influence each other, until at the extreme limit of their journey we get the characteristic French sequence, which for so long was used as a standard for the rest of the world. Meanwhile, along the fringes of the original provinces interpenetration necessarily takes place, and we find the Upper Gravettian filtering along the valleys of the Zagros Arc into southern Kurdistan, while the Aurignacian penetrates northward into the Crimea. Finally, at the close of the Pleistocene, migration on a large scale comes to an end, and numerous local variations spring up all over the Palæolithic world.

Outside all this, meanwhile, lies the still mysterious Far Eastern province, with its mixed flake and blade culture. In its early stages this may conceivably have played a part in the evolution of the Aurignacian proper, and in this connexion it is perhaps significant that Gordon Childe reports the presence of a slit-base bone point at Malta.

The picture which $I$ have outlined is admittedly largely speculative. I am prepared to be accused of domination by a mirage orientale, but to that I would reply that some of my colleagues seem to me at the moment to be unduly influenced by a mirage africain. Only further discovery will make it possible to decide between us.

\section{Obituary}

\section{Dr. George Forbes, F.R.S.}

$\mathrm{D}^{\mathrm{n}}$ . GEORGE FORBES, who died at Worthing on October 22 at eighty-seven years of age, was a well-known electrical engineer in the early days of electric lighting and electrical transmission of power. He was a man of great versatility, and in addition to electrical engineering work he did much useful physical research and was also greatly interested in astronomy. He was an intimate friend of the late Sir David Gill, formerly H.M. Astronomer at the Cape of Good Hope.

After taking his degree at Cambridge, Forbes was appointed professor of natural philosophy at Anderson's College, Glasgow, and occupied the chair from 1872 until 1880. One of his chief pieces of physical work was an extensive research on the velocity of light, carried out in conjunction with Dr. T. Young, between 1876 and 1880 and described in the Phil. Trans. Roy. Soc. of 1882 . They used a modified form of Fizeau's method and an are lamp as a source of light, working over a Scotch loch for a distance of about 3-4 miles. The result they obtained was 301,382 kilometres per second, which is rather in excess of the best results of Michelson and others. The chief novelty of their work was that they found a supposed greater velocity for blue light than red by about 1.8 per cent. Astronomical observations give, however, a denial to such a conclusion and it has not been held to be valid. Forbes also took part in astronomical expeditions, and when only twenty. five years of age he conducted a British party to Hawaii to observe a transit of Venus with the object of determining the solar parallax and distance. He wrote an excellent small book in Benn's Sixpenny Library Series on "The Earth, the Sun, and the Moon"

When electric lighting work began in England in the early 'eighties of last century, after the invention of the carbon filament electric lamp by Edison and Swan, Forbes came to London and was adviser or manager of one of the then formed electric manufacturing companies. He made improvements in an arc lamp and invented an electric meter for alternating electric currents. One of his most permanent improvements was the application of hard graphitic carbon as brushes for electric motors. Before that time it was usual to employ brushes of brass or copper gauze or wire; but these caused unnecessary wear of the commutator. Forbes suggested brushes made of graphitic carbon in the same fashion as are lamp carbons, and this was a great improvement and is used almost entirely at the present day.

When the great scheme of utilizing the power of Niagara Falls for production of electric current was under consideration, Forbes was one of those (and also the writer of this notice as well) consulted by the projectors as to the system of generation to be employed. In 1891 there was an electrical exhibition at Frankfort-on-Main, and one of the most interest. ing features was the transmission of power electrically over a distance of 110 miles from Lauffen to Frankfort by means of three-phase alternating electric currents. This transmission comprised the use of 300 h.p. generated at 55 volts and a frequency of 40 cycles. The voltage was raised by transformers to 8,500 volts and reduced again at the receiving end. The success of this performance gave a great impulse to the vaster scheme of utilizing Niagara, and the Cataract Company was formed to carry it out. After taking numerous opinions, it was decided to employ two-phase alternating currents, and generators driven by turbines were constructed of 5,000 h.p. to generate at 5,000 volts for transmission at 11,000 volts to Buffalo and other cities. Forbes went to Niagara to superintend the electrical work. At present, nearly a million horse-power is taken from the Falls.

Forbes travelled extensively, and in 1877 acted as special correspondent of The Times during the RussoTurkish War. $\mathrm{He}$ was the recipient of many 